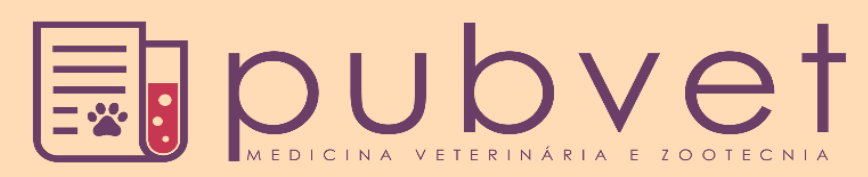

https://doi.org/10.31533/pubvet.v16n01a1025.1-7

\title{
Maior tempo de estocagem aumenta a digestibilidade do amido em silagem de milho?
}

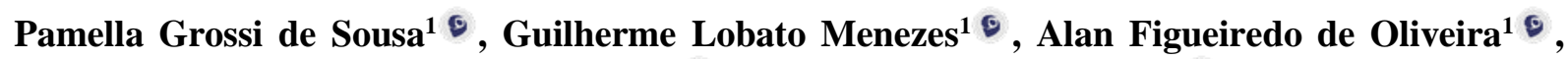 \\ Frederico Patrus Ananias de Assis Pires ${ }^{1 \bullet}$, Rafael Araújo de Menezes ${ }^{1}{ }^{\bullet}$, Eduarda Chaves de

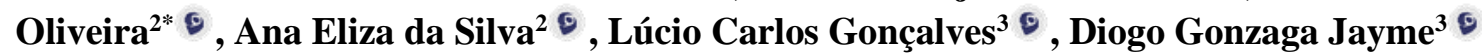 \\ ${ }^{1}$ Doutorando em Zootecnia, Escola de Veterinária da Universidade Federal de Minas Gerais. Belo Horizonte - MG, Brasil \\ ${ }^{2}$ Discente de Medicina Veterinária -Pontifícia Universidade Católica de Minas Gerais. Betim-MG, Brasil \\ ${ }^{3}$ Prof. Departamento de Zootecnia, Escola de Veterinária da Universidade Federal de Minas Gerais. Belo Horizonte - MG, Brasil \\ *Autor para correspondência.E-mail: eduardahchaves@gmail.com
}

\begin{abstract}
Resumo. O milho brasileiro é predominantemente duro (vítreo), e apresenta uma menor digestibilidade do amido em relação aos híbridos (farináceos). Para contornar esta situação, é realizada uma ensilagem, pois a degradabilidade efetiva do amido é maior em milho ensilado do que no milho fresco. O objetivo desta revisão é apresentar os efeitos do armazenamento prolongado da silagem na digestibilidade ruminal in vitro do amido. Um bom material estocado de silagem de milho irá contar com uma rápida queda do $\mathrm{pH}$, favorecendo a fermentação láctica. Quando se prolonga os dias de fermentação de 120 para 240 dias, é observado um aumento da concentração de acetato e lactato, o que pode justificar o aumento gradual da digestibilidade à medida que a fermentação progrediu. Apesar de ser um alimento energético, onde a proteína bruta não apresenta níveis importantes na silagem, esse parâmetro também apresentou aumento em sua concentração com um armazenamento prolongado, sugerindo implicação na formulação da dieta. O prolongamento da ensilagem tem uma relação positiva para a digestibilidade do amido, porém deve- se avaliar o efeito do tempo de armazenamento no desempenho animal.
\end{abstract}

Palavras chave: Armazenamento, ensilagem, fermentação

\section{Does longer storage time increase starch digestibility in corn silage?}

\begin{abstract}
Brazilian corn is predominantly hard (vitreous), and has a lower starch digestibility compared to hybrids (farinaceous). To overcome this situation, an ensiling is performed, as the effective degradability of starch is greater in ensiled corn than in fresh corn. The aim of this review is to present the effects of prolonged silage storage on in vitro ruminal starch digestibility. A good stocked corn silage material will have a rapid $\mathrm{pH}$ drop, favoring lactic fermentation. When the fermentation days are extended from 120 to 240 days, an increase in the acetate and lactate concentration is observed, which may justify the gradual increase in digestibility as the fermentation progressed. Despite being an energetic food, where the crude protein does not present important levels in the silage, this parameter also showed an increase in its concentration with prolonged storage, suggesting an implication in the diet formulation. The length of silage has a positive relationship for starch digestibility, but the effect of storage time on animal performance must be evaluated.
\end{abstract}

Key words: Storage, silage, fermentation

\section{Introdução}

As silagens de milho têm sido o principal volumoso conservado utilizado na alimentação de ruminantes (Neumann et al., 2017). O objetivo principal da ensilagem é preservar ao máximo o valor 
nutritivo do material original, devendo-se encher, compactar e selar o silo rapidamente, a fim de limitar a quantidade de oxigênio (Neumann et al., 2002).

De forma resumida, as bactérias anaeróbicas utilizam carboidratos solúveis como substrato para a fermentação e, por sua vez, produzem principalmente o lactato e o acetato. Com o acúmulo desses ácidos, o pH reduz até que a silagem atinja uma fase estável, onde mudanças mínimas ocorrem até a abertura do silo. Todavia, alguns estudos experimentais mostram algumas alterações no valor nutritivo da silagem com o armazenamento prolongado.

Em relação às características dos grãos, a vitreosidade é um parâmetro importante, pois representa a proporção de endosperma vítreo e farináceo do grão. O endosperma é classificado com base na distribuição dos grânulos de amido e da matriz proteica. No farináceo, os grânulos de amido são arredondados e estão dispersos, não havendo matriz proteica circundando essas estruturas. Já no endosperma vítreo, a matriz proteica é densa, com corpos proteicos estruturados, que circundam os grânulos de amido de formato poligonal, não permitindo espaços entre estas estruturas (Paes, 2006).

A digestibilidade do amido é principalmente influenciada pela matriz de amido-proteína em torno dos grânulos de amido que dificulta a fixação microbiana e a digestão ruminal ou hidrolítica e enzimática no abomaso e intestino delgado (Gerlach et al., 2018; Giuberti et al., 2014).

De acordo com Correa et al. (2002) o milho cultivado no Brasil é predominantemente duro (vítreo) e mais propenso a redução na digestibilidade do amido em situação de colheita tardia para silagem em relação aos híbridos dentados (farináceo). O amido compõe aproximadamente $70 \%$ da matéria seca (MS) do grão milho e é uma importante fonte de energia para os ruminantes. A digestibilidade total do amido da silagem de milho varia de 80 a $98 \%$ em vacas leiteiras em lactação alimentadas com dietas baseadas neste volumoso (Ferraretto \& Shaver, 2012). Dessa forma, objetivou-se apresentar os efeitos do armazenamento prolongado da silagem sobre a digestibilidade ruminal in vitro do amido.

\section{Matriz amido-proteína}

A matriz amido-proteína no milho é definida como um impedimento físico-químico ao amido à digestão microbiana em ruminantes (McAllister et al., 1993).

As proteínas (zeínas) que estão localizadas entre os grânulos de amido, são classificadas como prolaminas, com quatro subclasses $(\alpha, \beta, \gamma, \delta)$. À medida que as proteínas zeínas se desenvolvem e se distendem com o avanço maturidade, ligações cruzadas de $\beta$ e $\gamma$-zeínas e $\alpha$ - e $\delta$-zeínas penetram sua rede, encapsulando o amido numa matriz de proteína amido hidrofóbica (Buchanan et al., 2015). Essa matriz-proteica dificulta o acesso das enzimas e microrganismos aos grânulos de amido, aumenta a vitreosidade do endosperma e consequentemente diminui a digestibilidade.

\section{Perfil de fermentação}

Uma fermentação eficiente para conservar a forragem ensilada deve ser capaz de determinar a rápida queda do $\mathrm{pH}$ do material estocado. Tal evento requer ambiente anaeróbico, população suficiente de bactérias produtoras de ácido lático e nível adequado de substrato na forma de carboidratos solúveis (McDonald, 1981).

Segundo Tomich et al. (2003), os principais parâmetros utilizados para classificar a silagem como de ótima qualidade são: MS entre 30-35\%, pH inferior a 4,2, nitrogênio amoniacal em relação ao nitrogênio total (N-NH3/NT) inferior a 10\%, ácido lático superior a 5\% e ácido acético e ácido butírico inferior a $2,5 \%$ e $0,1 \%$, respectivamente.

Alguns estudos que testaram o armazenamento prolongado relataram que o $\mathrm{pH}$ continuou a diminuir ao longo do tempo devido ao acúmulo de lactato e acetato, mas esses efeitos não foram tão pronunciados no período inicial de estocagem. Por exemplo, dois estudos de silagem de planta inteira de milho (Ferraretto, et al., 2015; Ferraretto et al., 2016) destacaram quedas de $\mathrm{pH}$ em até 120 dias de ensilagem. Além disso, Windle et al. (2014) relataram um declínio do $\mathrm{pH}$ ao longo do tempo em armazenamento para a silagem de planta inteira de milho por até 150 dias, enquanto (Der Bedrosian et al., 2012) observaram queda de pH somente após 180 dias após a ensilagem (em silagem com 41\% de MS). 
O padrão de fermentação pode mudar do lactato para o acetato, dependendo da população natural existente no silo. Ferraretto et al. (2016) observaram um aumento nas concentrações de acetato e 1,2propanodiol de 30 a 120 dias de ensilagem, mas nenhuma alteração na concentração de lactato foi observada. Os autores atribuíram esses efeitos a mudança na população bacteriana epifítica, uma vez que não foram utilizados inoculantes microbianos heterofermentativos. Resultados semelhantes podem ocorrer dependendo do inoculante microbiano utilizado na ensilagem.

As Proteínas zeínas da matriz proteica do amido podem ser degradadas no processo de ensilagem por solubilização ou por atividade proteolítica. As proteínas zeínas são intensamente hidrofóbicas e insolúveis em água ou líquido ruminal, mas são solúveis em ácido láctico e ácido acético (Lawton, 2002). Como a fermentação produz ácido lático e acético, as zeínas hidrofóbicas na matriz proteica pode simplesmente ser solubilizadas (Hoffman et al., 2011). Ferraretto et al. (2015b) observaram um aumento na concentração de lactato (aumento de 19\%) e acetato (aumento de 58,6\%) de 30 a 240 dias de ensilagem. Este resultado pode justificar boa parte do aumento da digestibilidade ruminal in vitro do amido (aumento de 14,5\%).

\section{Proteólise}

A proteólise também é um mecanismo da fermentação de silagem de milho, que induz a degradação de proteínas e é melhor definida como degradação articular de proteínas por meio de proteases bacterianas (Vierstra, 1996). Dessa forma, proteínas zeína da matriz proteica podem ser degradadas pela atividade proteolítica na silagem de milho.

Ferraretto et al. (2014) e Kung Junior et al. (2014) indicam que a ensilagem prolongada aumenta a digestibilidade ruminal in vitro do amido, ressaltando que a digestibilidade máxima do amido ocorre somente após vários meses de armazenamento.

Peyrat et al. (2014) observaram que a degradabilidade efetiva do amido foi maior no milho ensilado $\left(83 \% \mathrm{~h}^{-1}\right)$ do que no milho fresco $\left(68 \% \mathrm{~h}^{-1}\right)$, possivelmente devido à hidrólise parcial dos grânulos encapsulados na matriz proteica durante o processo de fermentação induzida pela silagem. Estes dados sugerem que as proteases no silo foram responsáveis pela degradação da matriz proteica em grãos de milho. Como a matriz proteica é hidrofóbica e representa uma barreira físico-química para os microrganismos ruminais amilolíticos, sugere-se a degradação da matriz com o armazenamento prolongado para melhorar a digestibilidade ruminal do amido (Hoffman et al., 2011).

O experimento de Ferraretto (2015) avaliaram o tempo de armazenamento prolongado em silagem de milho de alta umidade (média de $72 \% \mathrm{MS}$ ) relataram aumento gradual na digestibilidade do amido à medida que a fermentação progrediu. Ferraretto et al. (2015b) e Hoffman et al. (2011), avaliaram a digestibilidade ruminal in vitro do amido (DRIV do amido) aos 30 ou 45 dias de estocagem, observaram aumento de 7 unidades percentuais na DRIV do amido. Esses estudos também mostraram aumento gradual no DRIV do amido (aproximadamente 4\%) após 60 a 90 dias de estocagem. Relações lineares positivas foram observadas entre a DRIV do amido e a $\mathrm{N}$-amoniacal $\left(\mathrm{N}-\mathrm{NH}_{3}\right)$ ou a proteína bruta solúvel (PB solúvel) nas ambas silagens de grão úmido (Ferraretto et al., 2014) e silagem de planta inteira de milho (Ferraretto et al., 2015c). Além disso, Ferraretto et al. (2014) relataram relações lineares negativas entre DRIV do amido em silagem de grão úmido e $\mathrm{pH}$ e positivas entre DRIV do amido e o $\mathrm{N}_{-} \mathrm{NH}_{3}$ e a PB solúvel. Estes resultados mostram que os principais mecanismos, solubilização e proteólise, são responsáveis pelo rompimento das proteínas zeína em torno dos grânulos de amido que ocorrem sob condições ácidas.

Um estudo realizado por Junges et al. (2017) com silagem de milho revelou que a atividade proteolítica no silo era principalmente de bactérias (60\%), seguida de enzimas do núcleo (30\%), dos fungos (5\%) e dos produtos de fermentação (5\%). A diminuição contínua do $\mathrm{pH}$ e o acúmulo de ácidos juntamente com a fermentação favorece a atividade de proteases vegetais específicas para o endosperma dos grãos de cereais (Simpson, 2001), embora geralmente a atividade das proteases vegetais seja reduzida sob baixo $\mathrm{pH}$. Além disso, as proteínas zeína são solúveis nos ácidos acético e lático (Lawton, 2002), os dois principais produtos finais de fermentação da ensilagem (Muck, 2010).

Com base nesses achados, o N-NH $\mathrm{NH}_{3}$ foi sugerido em combinação com tamanho de partícula para modelar os efeitos da maturidade, do teor de MS e a duração da fermentação na silagem na 
digestibilidade ruminal e taxa de degradação ruminal do amido para a silagem de grão úmido na alimentação (Hoffman et al., 2011). Uma abordagem semelhante seria quanto à silagem de planta inteira de milho, mas a previsão da digestibilidade do amido através do uso de $\mathrm{N}-\mathrm{NH}_{3}$ ou da $\mathrm{PB}$ solúvel como indicadores é provavelmente comprometida pela proteólise que ocorre na fração da folhagem.

Apesar da PB não ser um nutriente importante na silagem de milho (geralmente dentro de 5 a $9 \%$ da MS), aumento na concentração de $\mathrm{PB}$ solúvel e $\mathrm{N}-\mathrm{NH}_{3}$ com armazenamento prolongado foram sugeridos como potenciais implicações na formulação dietética (Gerlach et al., 2018). Até o momento, não existem estudos publicados que avaliem os efeitos do tempo de armazenamento no desempenho animal.

Um uso potencial do tempo de armazenamento como prática de manejo seria diminuir os efeitos negativos de fatores conhecidos por prejudicar a digestibilidade do amido, como a maturação na colheita e o tipo de endosperma do híbrido. Ferraretto et al. (2015b) avaliaram a interação entre o tipo híbrido e o tempo de ensilagem em que três híbridos de silagem de planta inteira de milho foram ensilados por 0 , 30, 120 e 240 dias. Perfis de fermentação, o N-NH 3 e a PB solúvel e a DRIV do amido foram similares para os dois tipos híbridos. Os aumentos nos teores de $\mathrm{N}^{-\mathrm{NH}_{3}}(+85 \%)$ e PB solúvel $(+47,5 \%)$ na silagem foram acompanhados por aumentos na DRIV do amido $(+14,5 \%)$ em resposta ao aumento do tempo de ensilagem, comparando 30 dias com 240 dias de ensilagem.

Os efeitos do tempo de ensilagem e da adição de protease exógena quanto ao perfil de fermentação, das frações de $\mathrm{N}$ e a DRIV do amido na silagem de planta inteira de milho de vários híbridos, maturidades e altura de corte foram avaliados por Ferraretto et al. (2015b). O tempo prolongado de armazenamento aumentou $(\mathrm{p}=0,001)$ a $\mathrm{N}-\mathrm{NH}_{3}(+84,9 \%)$, a PB solúvel $(+54 \%)$ e a DRIV do amido $(14,5 \%)$ na silagem de planta inteira de milho de vários híbridos. No entanto, o tempo de ensilagem prolongado não atenuou os efeitos negativos da vitreosidade e da maturidade da planta na colheita quanto à DRIV do amido. A protease exógena atenuou, mas não superou os efeitos negativos, com relação a DRIV do amido, da maturidade na silagem de planta inteira de milho. Young et al. (2012) também avaliaram o efeito da adição de protease exógena ao milho integral na ensilagem e observaram aumento na DRIV do amido (+9,5\%). Windle et al. (2014) também relataram que houve aumento da DRIV do amido mesmo com milho de maturação tardia.

\section{Escore de processamento da silagem de milho}

A eficácia do processamento do grão na silagem é uma variável e pode ser influenciada pela maturidade ou pelo conteúdo de MS da silagem de milho na colheita, o tamanho de partícula, o tipo de processador e a manutenção do processador de grãos (Ferraretto et al., 2012; Ferraretto \& Shaver, 2012).

Ferreira \& Mertens (2005) estabeleceram uma metodologia para determinar o grau de processamento do grão na silagem de milho, definida como escore de processamento da silagem de milho (EPSM). Essa metodologia é amplamente utilizada para medir a proporção de amido que passa por uma peneira de 4,75 $\mathrm{mm}$ após procedimentos de separação por agitação vertical usando amostras secas de silagem de milho.

Embora a hidrólise das proteínas zeína permita grande exposição dos grânulos de amido à fermentação microbiana e à digestão enzimática (McAllister et al., 1993), talvez um efeito secundário possa exacerbar essa resposta na ensilagem. O rompimento da matriz amido-proteína durante a ensilagem pode dissociar os grânulos de amido e, assim, reduzir o tamanho médio das partículas dos grãos (partículas menores são mais digeríveis) (Dias Junior et al., 2016).

Ferraretto et al. (2015d) realizaram dois estudos para avaliar o efeito da ensilagem e do armazenamento prolongado no EPSM. O primeiro experimento relatou aumento de 10 unidades percentuais na EPSM para a silagem fermentada por 30 dias em comparação com o material não fermentado (60,1\% vs. 50,2\%, respectivamente). Esses dados confirmam a hipótese de que a quebra das proteínas zeínas durante a fermentação (Hoffman et al., 2011) resultam na dissociação dos grânulos de amido e, com isso, reduz o tamanho das partículas dos grãos. O segundo experimento foi projetado para explicar os efeitos do armazenamento prolongado no EPSM da silagem de planta inteira de milho. O aumento gradual no EPSM de 0 a 240 dias de fermentação foi observado, similar ao que comumente ocorre com a digestibilidade do amido, $\mathrm{N}^{-\mathrm{NH}_{3}}$ e PB solúvel. Estas descobertas destacam os efeitos potenciais da fermentação prolongada, não apenas nas características químicas, mas também físicas dos grãos. No entanto, a extensão do aumento em EPSM no segundo experimento foi de menor magnitude 
do que no primeiro experimento. Talvez a magnitude da mudança na EPSM à medida que a fermentação avança dependa dos valores iniciais das amostras não fermentadas ou de outros fatores, e mais pesquisas são necessárias.

Com base nesses achados, a hipótese de Ferraretto et al. (2015d), era que a ensilagem melhoraria o EPSM em menor grau $(<50 \%$ de amido passando por peneira de $4,75 \mathrm{~mm})$ em comparação com adequado ou ótimo (> $50 \%$ ou $70 \%$ de amido passando por peneira de $4,75 \mathrm{~mm}$, respectivamente) da silagem processada. No entanto, é importante destacar que a duração prolongada do armazenamento não substituirá o processamento adequado na colheita.

\section{Considerações finais}

Estudos realizados com o tempo de ensilagem prolongado, comprovaram que existe relação positiva entre tempo de ensilagem e digestibilidade do amido. No entanto, existe a necessidade de mais estudos com milho de característica mais vítrea e milhos mal processados em silagem, pois o aumento do tempo de ensilagem talvez seja uma forma de melhorar as silagens brasileiras. Além disso deve-se avaliar o efeito do tempo de armazenamento no desempenho animal.

\section{Referências bibliográficas}

Buchanan, B. B., Gruissem, W., \& Jones, R. L. (2015). Biochemistry and molecular biology of plants. John wiley \& sons.

Correa, C. E. S., Shaver, R. D., Pereira, M. N., Lauer, J. G., \& Kohn, K. (2002). Relationship between corn vitreousness and ruminal in situ starch degradability. Journal of Dairy Science, 85(11), 30083012.

Der Bedrosian, M. C., Nestor Jr, K. E., \& Kung Junior, L. (2012). The effects of hybrid, maturity, and length of storage on the composition and nutritive value of corn silage. Journal of Dairy Science, 95(9), 5115-5126. https://doi.org/10.3168/jds.2011-4833.

Dias Junior, G. S., Ferraretto, L. F., Salvati, G. G. S., Resende, L. C., Hoffman, P. C., Pereira, M. N., \& Shaver, R. D. (2016). Relationship between processing score and kernel-fraction particle size in whole-plant corn silage. Journal of Dairy Science, 99(4), 2719-2729. https://doi.org/10.3168/jds.2015-10411.

Ferraretto, L. F., Crump, P. M., \& Shaver, R. D. (2015b). Effect of ensiling time and exogenous protease addition to whole-plant corn silage of various hybrids, maturities, and chop lengths on nitrogen fractions and ruminal in vitro starch digestibility. Journal of Dairy Science, 98(12), 8869-8881. https://doi.org/10.3168/jds.2015-9511.

Ferraretto, L. F., Dias Junior, G. S. D., Resende, L. C., \& Shaver, R. D. (2015d). Effect of ensiling on kernel processing score in wholeplant corn silage harvested with varied processors and settings. Journal of Dairy Science, 98(Suppl. 2), 689.

Ferraretto, L. F., Fredin, S. M., Muck, R. E., \& Shaver, R. D. (2016a). Case Study: Microbial inoculant and ensiling time effects on fermentation profile, nitrogen fractions, and ruminal in vitro and in situ starch digestibility in corn shredlage and late-maturity corn silage. The Professional Animal Scientist, 32(6), 861-868. https://doi.org/10.15232/pas.2016-01546.

Ferraretto, L. F., Fredin, S. M., \& Shaver, R. D. (2015a). Influence of ensiling, exogenous protease addition, and bacterial inoculation on fermentation profile, nitrogen fractions, and ruminal in vitro starch digestibility in rehydrated and high-moisture corn. Journal of Dairy Science, 98(10), 7318 7327. https://doi.org/10.3168/jds.2015-9891.

Ferraretto, L. F., \& Shaver, R. D. (2012). Meta-analysis: Effect of corn silage harvest practices on intake, digestion, and milk production by dairy cows. The Professional Animal Scientist, 28(6), 639-647. https://doi.org/10.15232/S1080-7446(15)30423-X

Ferraretto, L. F., Shaver, R. D., \& Bertics, S. J. (2012). Effect of dietary supplementation with live-cell yeast at two dosages on lactation performance, ruminal fermentation, and total-tract nutrient digestibility in dairy cows. Journal of Dairy Science, 95(7), 4017-4028. https://doi.org/http://dx.doi.org/10.3168/jds.2011-5190 
Ferraretto, L. F., Shaver, R. D., Massie, S., Singo, R., Taysom, D. M., \& Brouillette, J. P. (2015c). Effect of ensiling time and hybrid type on fermentation profile, nitrogen fractions, and ruminal in vitro starch and neutral detergent fiber digestibility in whole-plant corn silage. The Professional Animal Scientist, 31(2), 146-152. https://doi.org/10.15232/pas.2014-01371.

Ferraretto, L. F., Taysom, K., Taysom, D. M., Shaver, R. D., \& Hoffman, P. C. (2014). Relationships between dry matter content, ensiling, ammonia-nitrogen, and ruminal in vitro starch digestibility in high-moisture corn samples. Journal of Dairy Science, 97(5), 3221-3227. https://doi.org/10.3168/jds.2013-7680.

Ferreira, G., \& Mertens, D. R. (2005). Chemical and physical characteristics of corn silages and their effects on in vitro disappearance. Journal of Dairy Science, 88(12), 4414-4425. https://doi.org/10.3168/jds.S0022-0302(05)73128-3.

Gerlach, K., Pfau, F., Pries, M., Hünting, K., Weiß, K., Richardt, W., \& Südekum, K. H. (2018). Effects of length of ensiling and maturity group on chemical composition and in vitro ruminal degradability of whole-crop maize. Grass and Forage Science, 73(3), 599-609. https://doi.org/10.1111/gfs.12362.

Giuberti, G., Gallo, A., Masoero, F., Ferraretto, L. F., Hoffman, P. C., \& Shaver, R. D. (2014). Factors affecting starch utilization in large animal food production system: A review. Starch-Stärke, 66(12), 72-90. https://doi.org/10.1111/gfs.12362.

Hoffman, P. C., Esser, N. M., Shaver, R. D., Coblentz, W. K., Scott, M. P., Bodnar, A. L., Schmidt, R. J., \& Charley, R. C. (2011). Influence of ensiling time and inoculation on alteration of the starchprotein matrix in high-moisture corn. Journal of Dairy Science, 94(5), 2465-2474. https://doi.org/http:dx.doi.org/10.3168/jds.2010-3562.

Junges, D., Morais, G., Spoto, M. H. F., Santos, P. S., Adesogan, A. T., Nussio, L. G., \& Daniel, J. L. P. (2017). Influence of various proteolytic sources during fermentation of reconstituted corn grain silages. Journal of Dairy Science, 100(11), 9048-9051. https://doi.org/10.3168/jds.2017-12943.

Kung Junior, L., Windle, M. C., \& Walker, N. (2014). The effect of an exogenous protease on the fermentation and nutritive value of high-moisture corn. Journal of Dairy Science, 97(3), 1707-1712. https://doi.org/10.3168/jds.2013-7469.

Lawton, J. W. (2002). Zein: A history of processing and use. Cereal Chemistry, 79(1), 1-18. https://doi.org/10.1094/CCHEM.2002.79.1.1.

McAllister, T. A., Phillippe, R. C., Rode, L. M., \& Cheng, K.-J. (1993). Effect of the protein matrix on the digestion of cereal grains by ruminal microorganisms. Journal of Animal Science, 71(1), 205212. https://doi.org/10.2527/1993.711205x.

McDonald, P. (1981). The biochemistry of silage. John Wiley \& Sons, Ltd.

Muck, R. E. (2010). Silage microbiology and its control through additives. Revista Brasileira de Zootecnia, $\quad 39$ (Supl), 183-191. $\quad$ https://doi.org/http://dx.doi.org/10.1590/S151635982010001300021.

Neumann, M., Leão, G. F. M., Coelho, M. G., Figueira, D. N., Spada, C. A., \& Perussolo, L. F. (2017). Aspectos produtivos, nutricionais e bioeconômicos de híbridos de milho para produção de silagem. Archivos de Zootecnia, 66(253), 51-57.

Neumann, M., Restle, J., Alves Filho, D. C., Brondani, I. L., Pellegrini, L. G., \& Freitas, A. K. (2002). Avaliação do valor nutritivo da planta e da silagem de diferentes híbridos de sorgo (Sorghum bicolor, L. Moench). Revista Brasileira de Zootecnia, 31(1), 293-301.

Paes, M. C. D. (2006). Aspectos físicos, químicos e tecnológicos do grão de milho. Embrapa Milho e Sorgo-Circular Técnica.

Peyrat, J., Nozière, P., Le Morvan, A., Férard, A., Protin, P.-V., \& Baumont, R. (2014). Effects of ensiling maize and sample conditioning on in situ rumen degradation of dry matter, starch and fibre. Animal Feed Science and Technology, 196, 12-21. https://doi.org/10.1016/j.anifeedsci.2014.06.017.

Simpson, D. J. (2001). Proteolytic degradation of cereal prolamins - the problem with proline. Plant Science, 161(5), 825-838. https://doi.org/10.1016/S0168-9452(01)00482-4. 
Tomich, T. R., Pereira, L. G. R., Gonçalves, L. C., Pinto, T. R. G., \& Orges, I. (2003). Características químicas para avaliação do processo fermentativo de silagens: uma proposta para qualificação da fermentação. Embrapa Pantanal-Documentos, 57, 20.

Vierstra, R. D. (1996). Proteolysis in plants: mechanisms and functions. Post-Transcriptional Control of Gene Expression in Plants, 275-302.

Windle, M. C., Walker, N., \& Kung Jr, L. (2014). Effects of an exogenous protease on the fermentation and nutritive value of corn silage harvested at different dry matter contents and ensiled for various lengths of time. Journal of Dairy Science, 97(5), 3053-3060. https://doi.org/10.3168/jds.2013-7586.

Young, K.M. et al. Effect of exogenous protease enzymes on the fermentation and nutritive value of corn silage. J. Dairy Sci., v. 95, n. 11, p. 6687-6694, 2012. DOI: https://doi.org/10.3168/jds.2012$\underline{5628}$

\section{Histórico do artigo:}

Recebido: 10 de setembro de 2021

Aprovado: 8 de outubro de 2021

Disponível online: 30 de janeiro de 2022
Licenciamento: Este artigo é publicado na modalidade Acesso Aberto sob a licença Creative Commons Atribuição 4.0 (CC-BY 4.0), a qual permite uso irrestrito, distribuição, reprodução em qualquer meio, desde que o autor e a fonte sejam devidamente creditados. 